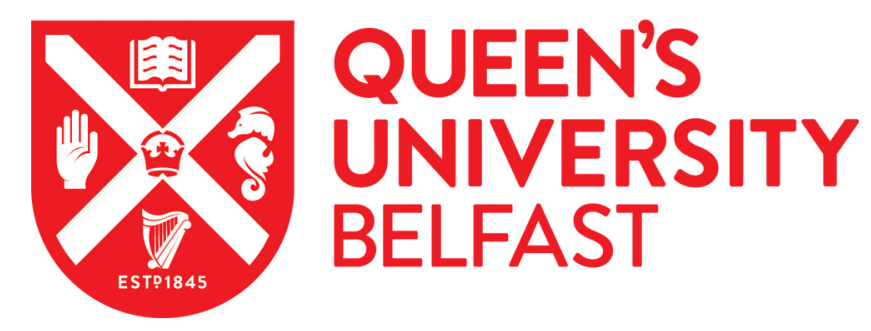

\title{
The cost-effectiveness of azithromycin in reducing exacerbations in uncontrolled asthma
}

O'Neill, C., Gibson, P. G., Heaney, L. G., Upham, J. W., Yang, I. A., Reynolds, P. N., Hodge, S., Jenkins, C. R., Peters, M., Marks, G. B., James, A. L., \& Simpson, J. L. (2020). The cost-effectiveness of azithromycin in reducing exacerbations in uncontrolled asthma. European Respiratory Journal, 57(2), [02436-2020]. https://doi.org/10.1183/13993003.02436-2020, https://doi.org/10.1183/13993003.02436-2020

Published in:

European Respiratory Journal

Document Version:

Peer reviewed version

Queen's University Belfast - Research Portal:

Link to publication record in Queen's University Belfast Research Portal

Publisher rights

Copyright CERS 2020. This work is made available online in accordance with the publisher's policies. Please refer to any applicable terms of use of the publisher.

\section{General rights}

Copyright for the publications made accessible via the Queen's University Belfast Research Portal is retained by the author(s) and / or other copyright owners and it is a condition of accessing these publications that users recognise and abide by the legal requirements associated with these rights.

Take down policy

The Research Portal is Queen's institutional repository that provides access to Queen's research output. Every effort has been made to ensure that content in the Research Portal does not infringe any person's rights, or applicable UK laws. If you discover content in the Research Portal that you believe breaches copyright or violates any law, please contact openaccess@qub.ac.uk. 
The cost-effectiveness of azithromycin in reducing exacerbations in uncontrolled asthma.

Ciaran O'Neill ${ }^{1}$, Peter G Gibson ${ }^{2,3}$ Liam G Heaney $^{4}$, John W Upham ${ }^{5,6}$, lan A Yang ${ }^{5,7}$, Paul N Reynolds ${ }^{8}$, Sandra Hodge ${ }^{9}$, Christine R Jenkins ${ }^{10}$, Matthew Peters ${ }^{11}$, Guy B Marks ${ }^{12}$, Alan L James ${ }^{13,14}$, Jodie L

\section{Simpson ${ }^{2,3}$}

1. Centre for Public Health, Queen's University Belfast, UK

2. Priority Research Centre for Healthy Lungs, Faculty of Health and Medicine, Hunter Medical Research Institute and University of Newcastle, NSW Australia

3. Department of Respiratory and Sleep Medicine, Hunter New England Area Health Service, John Hunter Hospital, Newcastle NSW Australia

4. Centre for Experimental Medicine, School of Medicine, Dentistry and Biomedical Sciences, Queen's University Belfast, UK

5. Faculty of Medicine, The University of Queensland, St Lucia, QLD, Australia

6. Translational Research Institute, Princess Alexandra Hospital, Woolloongabba, QLD, Australia

7. Department of Thoracic Medicine, The Prince Charles Hospital, Chermside, QLD, Australia

8. School of Medicine, The University of Adelaide, Adelaide, SA, Australia

9. Department of Thoracic Medicine, Lung Research Unit, Royal Adelaide Hospital, Adelaide, SA, Australia

10. Respiratory Trials, The George Institute for Global Health, Sydney, NSW, Australia; Department of Thoracic Medicine, Concord General Hospital, Sydney, NSW, Australia

11. Faculty of Medicine and Health Sciences, Macquarie University, Sydney, NSW, Australia; Department of Thoracic Medicine, Concord General Hospital, Sydney, NSW, Australia

12. Woolcock Institute of Medical Research, Sydney, NSW, Australia; South Western Sydney Clinical School, University of New South Wales, Sydney, NSW, Australia

13. School of Medicine and Pharmacology, University of Western Australia, Crawley, WA, Australia

14. Department of Pulmonary Physiology and Sleep Medicine, Sir Charles Gairdner Hospital, Nedlands, WA, Australia

Corresponding Author:

Jodie Simpson

Level 2 East, Hunter Medical Research Institute

Lot 1 Kookaburra circuit, New Lambton NSW 2305 Australia

Jodie.simpson@newcastle.edu.au

\section{Take home message}

Add-on AZM in the treatment of poorly controlled persistent asthma is cost-effective. It is associated with a positive net monetary benefit when costs including those associated with antimicrobial resistance were considered. 


\section{Abstract}

2 Add-on azithromycin (AZM) results in a significant reduction in exacerbations among adults with persistent

3 uncontrolled asthma. The aim of this study was to assess the cost-effectiveness of add-on AZM in terms of 4 healthcare and societal costs.

6 The AMAZES trial randomly assigned 420 participants to AZM or placebo. Healthcare use and asthma

7 exacerbations were measured during the treatment period. Healthcare use included all prescribed medicine 8 and healthcare contacts. Costs of antimicrobial resistance (AMR) were estimated based on overall 9 consumption and published estimates of costs. The value of an avoided exacerbation was based on 10 published references. Differences in cost between the two groups were related to differences in 11 exacerbations in a series of net monetary benefit estimates. Societal costs included lost productivity, over 12 the counter medicines, steroid induced morbidity and AMR costs.

14 Add-on AZM resulted in a reduction in healthcare costs (mean $(95 \% \mathrm{CI}))$ including nights in hospital 15 (\$433.70 (\$48.59 - \$818.81) or €260.22(€29.15 - €491.29)), unplanned healthcare visits (\$20.25 (\$5.23$16 \$ 35.27)$ or $€ 12.15(€ 3.14-€ 21.16))$, antibiotic costs $(\$ 14.88(\$ 7.55-\$ 22.21)$ or $€ 8.93(€ 4.53-€ 13.33))$ and 17 oral corticosteroid costs $(\$ 4.73(\$ 0.82-\$ 8.64)$ or $€ 2.84(€ 0.49-€ 5.18))$, all $p<0.05$. Overall healthcare and 18 societal costs were lower $(\$ 77.30(€ 46.38)$ and $\$ 256.22(€ 153.73)$ respectively) albeit not statistically 19 significant. The net monetary benefit of add-on AZM was estimated to be $\$ 2072.30$ (95\% CI $\$ 1348.55$ $\$ 2805.23)$ or $(€ 1243.38$ ( $€ 809.13-€ 1683.14)$ assuming a willingness to pay per exacerbation avoided of

$21 \$ 2651$ (€1590.60). Irrespective of the sensitivity analysis applied, the net monetary benefit for total,

22 moderate and severe exacerbations remained positive and significant.

24 Add-on AZM therapy in poorly controlled asthma was a cost-effective therapy. Costs associated with AMR 25 did not influence estimated cost-effectiveness. 


\section{Introduction}

Asthma is a highly prevalent disease affecting over 300 million people worldwide (1). It is associated with a significant economic burden $(2,3)$, a burden shown across a variety of healthcare systems to be concentrated among those with severe disease (4-7). Patients with severe asthma are known to be at increased risk of exacerbations $(8,9)$ and patients with severe asthma who experience exacerbations have been shown to incur approximately twice the asthma-related costs of patients with controlled severe disease as well as increased risks of morbidity and mortality $(9,10)$. Given the major impact of exacerbations on patients, there remains a global imperative to prevent asthma exacerbations.

Treatments used in this respect have included tiotropium $(11,12)$, T2-directed monoclonal antibody therapies (13-15) and oral corticosteroid therapy (16). While these have been shown to be effective, issues, such as cost in the case of monoclonal antibody therapies (17) and toxicity in the case of oral corticosteroid therapy (18) have called into question their potential for widespread use. In addition, while studies of cost-effectiveness with respect to tiotropium as an add-on to standard therapy suggest its cost-effectiveness, these have been based on modelling exercises rather than trials and remain to be fully explored $(19,20)$.

Recent studies have explored the prophylactic use of macrolide antibiotics in the avoidance of exacerbations where asthma is severe or not completely controlled (21-23). The most recent study randomised patients to $500 \mathrm{mg}$ of oral azithromycin (AZM), taken three times per week for 48 weeks as an add on to standard therapy and compared to placebo in terms of the number of exacerbations (severe and moderate), time to first exacerbation and asthma-related quality of life over the course of a year. It found that the azithromycin group had significantly fewer exacerbations (1.07 per patient-year [95\% Cl 0.85-1.29]) compared with placebo $(1 \cdot 86$ per patient-year [1.54-2.18]), better asthma-related quality of life 
1 compared to the placebo group (adjusted mean difference, 0.36 [95\% Cl 0.21-0.52];

$2 p=0.001)$ and a longer interval before experiencing a first exacerbation than the placebo

3

6 The aim of this study was to estimate the cost-effectiveness of add-on azithromycin based

group. Based on the study results the authors concluded that azithromycin might be a useful add-on therapy in persistent asthma. on the AMAZES study (23) accounting for healthcare and other costs including estimated costs for potential antibiotic resistance associated with prophylactic use of AZM and other antibiotics prescribed during the study.

\section{Methods}

\section{Study Design}

Full details of the AMAZES trial are reported elsewhere including recruitment, exclusions, outcome measures and adverse events (23). Briefly, the trial was powered to detect a difference in the number of exacerbations between the AZM and placebo groups which was evaluated in 420 adults with symptomatic asthma despite current use of inhaled corticosteroid and long-acting bronchodilators: 213 and 207 to the AZM and placebo groups respectively. Differences in the primary and secondary outcomes were assessed on an intention to treat basis after 48 weeks treatment with oral AZM, 500mg, 3 times per week, or matching placebo. Adverse events observed over the course of the study and measures of antibiotic resistance were taken at the end of the study. In the original study exacerbations were expressed in terms of per person year, here we explore them simply in terms of the trial end point - i.e. after 48 weeks.

\section{Methods and Analyses}

In the cost-effectiveness analysis, data on healthcare use collected alongside outcomes were aggregated, monetised and related to outcomes in a series of incremental cost- 
effectiveness analyses from both a healthcare system and societal perspective. Resource use included the number of general practitioner (GP) visits, emergency room (ER) visits, hospital inpatient nights and drug use including both prescribed and those bought over the counter (OTC). Each aspect of cost was monetised using standard references for Australia and full details are provided in the online supplementary methods and Table S1. To take account of broader costs that may arise due to therapy, costs related to antimicrobial resistance (AMR) were estimated as were the costs related to corticosteroid induced morbidity and those related to productivity losses. Here recourse was made to the literature, with adjustments for purchasing power parity as detailed in the supplement.

Descriptive statistics for each element of resource, together with its associated cost were estimated for the AZM and placebo groups separately. Differences of means in cost and outcomes were estimated between the groups. The ratio of the difference in mean cost to mean effect (all exacerbations, severe and moderate exacerbations only) between groups were estimated as the incremental cost-effectiveness ratio between the AZM and placebo groups. To take account of the potential joint distribution of cost and effects a non-parametric approach was used to estimate incremental cost effectiveness ratios (ICER). The process was repeated for each outcome, total exacerbations (severe and moderate) as well as severe and moderate exacerbations only, separately and with respect to each cost measure, healthcare costs (excluding steroid induced morbidity, antimicrobial resistance, OTC and lost productivity costs) and societal costs (that is including steroid induced morbidity, antimicrobial resistance, OTC and lost productivity costs). Net monetary benefit estimates for moderate, severe and total exacerbations with respect to healthcare and societal costs based on an assumed willingness to pay per exacerbation avoided of \$2651 using an estimate by Lloyd et al (24) adjusted for purchasing power parity and updated for inflation were calculated. A cost-effectiveness acceptability curve with respect to societal costs and total exacerbations was estimated to capture uncertainty with respect to the willingness to 
pay for an avoided exacerbation. The probability of cost-effectiveness assuming a willingness to pay per avoided exacerbation ranging from 0 to $\$ 3,000$ was examined.

A series of sensitivity analyses were undertaken as detailed in the supplementary methods. Societal costs were winsorised at the $99^{\text {th }}$ centile for each group and net monetary benefits re-estimated. Winsorising data limits the effect of extreme values that might give rise to potentially spurious conclusions. Antimicrobial resistance costs were estimated at twice the upper bound of the range for cost per course provided in the literature to assess its potential impact on net monetary benefit estimates [5] relative to the base case analysis. Decrements in health-related quality of life associated with an exacerbation were estimated using the literature and monetised using a threshold willingness to pay of $\$ 64,000$ (AUS) per quality adjusted life-year (QALY). Estimates allowed for the severity of the exacerbation experienced. The net monetary benefit and the probability of the intervention being deemed cost-effective was re-estimated based on the difference in estimated QALY gain. Net monetary benefit was re-estimated for complete cases only, that is, where any censored observations were removed. As costs and outcomes were confined to 48 weeks discounting was not necessary.

\section{Results}

The descriptive statistics for healthcare use, medication costs and estimated antimicrobial resistance are shown in Table 1, all values are expressed in Australian dollars (AUS\$). Costs for general practitioner and emergency room visits as well as inpatient nights were lower in the AZM group. Similarly, cost of antibiotics and OCS prescriptions are around half that of the placebo costs for those treated with add-on AZM. Estimated costs for 
1 antimicrobial resistance was 6 times higher in the AZM group, while costs for OTC therapies

2 and asthma therapies were similar between the groups.

$4 \quad$ The difference between the groups subtracting AZM costs from placebo are presented in

5 Table 2. Those who received AZM had significantly reduced costs for visits with a physician

6 and inpatient nights as well as antibiotic requirements other than the intervention and OCS

7 treatment (Table 2). They also had lower total healthcare costs, though these failed to

8 achieve statistical significance. The cost of the AZM and estimated costs for antimicrobial resistance were significantly higher in the AZM group. Mean societal costs were lower in the AZM group than in the placebo group however, the difference was not statistically significant. This suggests add-on AZM is not more expensive relative to usual care but attains significantly better outcomes. The net reduction in societal costs due to AZM is greater than the saving in healthcare costs; with the inclusion of antimicrobial resistance costs being counterbalanced by the inclusion of corticosteroid induced morbidity and lost productivity costs.

The net monetary benefit which assesses the net value of the intervention was positive for total exacerbations (Table 3), that is, at an assumed willingness-to-pay of $\$ 2651$ per exacerbation (24) or $€ 1590.60$ based on an exchange rate of AUS\$1 $=€ 0.6$ current at the time of writing, add-on AZM has a positive net monetary value for both healthcare and societal costs. This is also the case for moderate and severe exacerbations when considered individually, both were positive and when added together the gain is the greatest. Healthcare and societal costs are lower, and exacerbations avoided higher in the AZM group, confirming AZM as an add-on therapy is less expensive and more effective. This is seen in Figure 1 showing the cost-effectiveness plane for costs versus total exacerbations, where both healthcare (Figure 1A) and societal costs (Figure 1B) are both in the South West quadrant of the plane signifying fewer exacerbations at a lower cost. 
2 The probability of add-on AZM being deemed to be cost-effective was further explored using 3 a cost effectiveness acceptability curve for total exacerbations and societal costs, shown in

4 Figure 2. The probability of AZM being cost-effective exceeded 0.95 at a willingness to pay 5 to avoid an exacerbation of $\$ 100$, approaching 1 at higher values.

6

7 Irrespective of the sensitivity analysis applied, the net monetary benefit for total, moderate and severe exacerbations remained positive and significant (Table 4). This process allowed examination of whether the results were robust to the role of outliers in the sample, the inflation of antimicrobial resistance costs or removal of censored observations.

\section{Discussion}

Asthma is a highly prevalent condition and among those with persistent asthma, exacerbations contribute significantly to its burden $(9,10)$. Various efforts have been made to reduce the burden associated with exacerbations (11-16) though issues of toxicity, cost and the robustness of evidence exist (17-20). Prophylactic use of AZM has been shown to be effective in reducing the total number of asthma exacerbations as well as the number of severe exacerbations while having no significant effect on serious adverse events and similar results in terms of prevalence of AZM-resistant organisms. (23) This study has shown that AZM as an-add on therapy is associated with a reduction in healthcare and societal cost, though the reduction is not statistically significant, while resulting in significant reductions in exacerbations. The increased cost of AZM was counterbalanced by the reductions in cost associated with fewer healthcare contacts and in particular those associated with inpatient stays and general practitioner visits. 
1 Evidence of the cost effectiveness is provided by the estimated net monetary benefit and

2 sensitivity analyses. The net monetary benefit at a willingness to pay of $\$ 2651$ per

3

4

5

6

7 exacerbation was positive (\$1910.70 (€1146.42) from a healthcare perspective) and statistically significant. Incorporating the estimated cost associated with antimicrobial resistance along with other societal costs/savings into the analysis did not materially affect the results (the net monetary benefit rising to $\$ 2072.30$ (€1243.38)). In addition, when we performed sensitivity analyses in which antimicrobial costs were inflated to the twice the upper bound of reported range per course, the net monetary benefit remained positive and statistically significant $(\$ 1700.68(€ 1020.41))$. The probability of AZM being considered costeffective approached 1 at a willingness to pay to avoid an exacerbation of $\$ 100-$ far in lower than that used in the base case analysis $(\$ 2651)$. The net monetary benefit remained positive and significant when based on an estimated value of QALY gain. When productivity losses were confined to those aged 65 and under NMB estimates remained virtually unchanged (results available on request from the authors). Overall, these results provide reassurance as to the robustness of the cost effectiveness of AZM as an add-on therapy to usual care.

While no significant difference was found in the prevalence of AZM-resistant organisms in the main study (23), the impact of inappropriate use of antibiotics on antimicrobial resistance is of concern given its potential health and economic impact globally (25). Our treatment of antimicrobial resistance costs were based on the use of the midpoint of the estimated cost per course range, the use of 48 weeks of AZM which would disadvantage the intervention in terms of cost and make conservative the cost effectiveness estimates. That the WHO continues to classify AZM as a key access antibiotic (designating it among those that should be widely available, affordable and quality assured) (26) notwithstanding, it remains among its Watch group i.e. those who stewardship should be prioritised. More generally a cautious approach to use of any antibiotic given its potential to increase antimicrobial resistance risks 
and costs is prudent and has been reflected in the approach we use. How high we should raise antimicrobial resistance costs to reflect such prudence lies beyond the scope of this paper. As noted, however, estimates of a positive net monetary benefit remained robust to a variety of assumptions regarding cost and the value of outcomes including the assumption that antimicrobial resistance costs were twice the upper bound estimate of the cost per course reported in the literature.

\section{Strengths and Limitations}

Strengths of the study include the detailed recording of healthcare use that allowed drug use to be estimated based on actual prescriptions including dose and frequency rather than simply cost per course of an assumed standard prescription. Our ability to include antimicrobial resistance, OCS and productivity losses are added strengths of the paper.

Limitations of the paper are also evident. The accuracy of antimicrobial resistance costs per course reported in the literature is open to challenge. That our results remain robust to the inflation of antimicrobial resistance to twice the upper bound of the reported cost range may offer some reassurance in this regard as may our other conservative treatments of antimicrobial resistance costs. It remains important to acknowledge the uncertainty that exists around this figure, however. Similarly, while we relied on average earnings to estimate productivity losses, we were conservative in our approach to their inclusion, assuming only days spent in hospital were lost to work rather than total sick days. The paucity of estimates regarding the willingness to pay to avoid an exacerbation is a further limitation. As shown by the cost effectiveness acceptability curve though, the probability that add-on azithromycin was cost effective continued to exceed 0.95 at WTPs of around $\$ 100$. The net monetary benefit also remained positive using alternative valuation approaches based on extrapolations. 


\section{Conclusion}

3 The study has shown that add-on oral AZM therapy is a cost-effective treatment for adults

4 with persistent asthma and poor control being associated with lower healthcare costs and

5 significantly fewer exacerbations. While due caution is warranted in the use of any antibiotic,

6 the estimated net monetary benefit remained positive and significant even when the costs of

7 antimicrobial resistance were inflated to twice the upper bound of the ranges used for their

8 costs. Based on these analyses the prophylactic use of 500mg AZM taken three times per

9 week to reduce exacerbations would appear to be cost-effective even allowing for a cautious

10 approach to the use of antibiotics.

11 Acknowledgements

12 We wish to acknowledge the comments of Professor Paddy Gillespie and Dr Grainne

13 Crealey NUI Galway and Dr Luke Barry Queen's University Belfast on an earlier draft of this

14 paper and of Nga Nguyen for advice on the analyses of prescribed medicine. We also wish

15 to acknowledge the AMAZES research group for undertaking the study as well as the

16 AMAZES study participants. 


\section{References}

1. Global Asthma Network. The Global Asthma Report. Auckland, New Zealand; 2014.

2. Mukherjee M, Stoddart A, Gupta RP, Nwaru BI, Farr A, Heaven M, Fitzsimmons D, Bandyopadhyay A, Aftab C, Simpson CR. The epidemiology, healthcare and societal burden and costs of asthma in the UK and its member nations: analyses of standalone and linked national databases. BMC medicine 2016; 14: 113.

3. Barnett SBL, Nurmagambetov TA. Costs of asthma in the United States: 2002-2007. Journal of Allergy and Clinical Immunology 2011; 127: 145-152.

4. Chastek B, Korrer S, Nagar SP, Albers F, Yancey S, Ortega H, Forshag M, Dalal AA. Economic Burden of IIIness Among Patients with Severe Asthma in a Managed Care Setting. J Manag Care Spec Pharm. 2016 Jul;22(7):848-61.

5. Flórez-Tanus Á, Parra D, Zakzuk J, Caraballo L, Alvis-Guzmán N Health care costs and resource utilization for different asthma severity stages in Colombia : a claims data analyis. World Allergy Organ J. 2018 Nov 12;11(1):26.

6. Lee YJ, Kwon SH, Hong SH, Nam JH, Song HJ, Lee JS, Lee EK, Shin JY. Health Care Utilization and Direct Costs in Mild, Moderate, and Severe Adult Asthma: A Descriptive Study Using the 2014 South Korean Health Insurance Database. Clin Ther. 2017 Mar;39(3):527-536

7. Suruki RY, Daugherty JB, Boudiaf N, Albers FC. The frequency of asthma exacerbations and healthcare utilization in patients with asthma from the UK and USA. BMC Pulm Med. 2017 Apr 27;17(1):74.

8. Calhoun WJ, Haselkorn T, Mink DR, Miller DP, Dorenbaum A, Zeiger RS. Clinical burden and predictors of asthma exacerbations in patients on guideline-based steps 4-6 asthma therapy in the TENOR cohort. J Allergy Clin Immunol Pract. 2014;2(2):193-200. 
19 Ivanova JI, Bergman R, Birnbaum HG, Colice GL, Silverman RA, McLaurin K. Effect of

2 asthma exacerbations on health care costs amongasthmatic patients with moderate and 3 severe persistent asthma. J Allergy Clin Immunol. 2012;129(5):1229-35.

410 Sullivan SD, Rasouliyan L, Russo PA, Kamath T, Chipps BE, Group TS. Extent, patterns, 5 and burden of uncontrolled disease in severe or difficult-to-treat asthma. Allergy. $6 \quad 2007 ; 62(2): 126-33$.

711 Kerstjens et al (see Randonovch) Kerstjens HA, Engel M, Dahl R, Paggiaro P, Beck E, 8 Vandewalker $\mathrm{M}$, et al. Tiotropium in asthma poorly controlled with standard combination 
118 Barry LE, O'Neill C, Patterson C, Sweeney J, Price D, Heaney LG. Age and Sex

2 Associations with Systemic Corticosteroid-Induced Morbidity in Asthma. J Allergy Clin

3 Immunol Pract. 2018 Nov - Dec;6(6):2014-2023.e2.

419 Willson J, Bateman ED, Pavord I, Lloyd A, Krivasi T, Esser D.

5 Cost effectiveness of tiotropium in patients with asthma poorly controlled on inhaled gluco

6 corticosteroids and long-acting $\beta$-agonists. Appl Health Econ Health Policy. 2014

$7 \quad$ Aug;12(4):447-59.

820 Willson J, Bateman ED, Pavord I, Lloyd A, Krivasi T, Esser D. Erratum

9 to: Cost Effectiveness of Tiotropium in Patients with Asthma Poorly Controlled on Inhaled

10 Glucocorticosteroids and Long-Acting $\beta$-Agonists. Appl Health Econ Health Policy. 2016

11 Feb;14(1):119-25.

21 Simpson J, Powell H, Boyle M, Scott R, Gibson P. Clarithromycin targets neutrophilic airway inflammation in refractory asthma. Am J Respir Crit Care Med 2008; 177: 148-55.

22 Brusselle GG, Vanderstichele C, Jordens $P$, et al. Azithromycin for prevention of exacerbations in severe asthma (AZISAST): a multicentre randomised double-blind placebo-controlled trial. Thorax 2013; 68: 322-29.

23 Gibson PG, Yang IA, Upham JW, Reynolds PN, Hodge S, James AL, et al. Effect of azithromycin on asthma exacerbations and quality

of Life in adults with persistent uncontrolled asthma (AMAZES): $\quad$ a randomised, doubleblind, placebo-controlled trial. Lancet. 2017 Aug 12;390(10095):659-668

24 Lloyd A, Mclntosh E, Rabe KF, Williams A. Patient preferences for asthma therapy: a discrete choice experiment. Primary Care Respiratory Journal (2007); 16(4): 241-248

25 O’Neill J. Tackling drug-resistant infections globally: final report and recommendations. The review on antimicrobial resistance. $2016 . \quad$ https://amrreview.org/sites/default/files/160518 Final\%20paper with\%20cover.pdf. Accessed December 2016. 
126 The World Health Organizations Model List of Essential Medicines. March 2017. 2 http://www.who.int/medicines/publications/essentialmedicines/en/. Accessed December 32019.

4 
2 Table 1: Descriptive statistics and healthcare costs according to treatment group

\begin{tabular}{|c|c|c|c|c|}
\hline & \multicolumn{2}{|c|}{ Azithromycin } & \multicolumn{2}{|c|}{ Placebo } \\
\hline \multirow[t]{2}{*}{$\mathrm{N}$} & \multicolumn{2}{|c|}{213} & \multicolumn{2}{|c|}{207} \\
\hline & Visits/nights/units & Cost & Visits/nights/units & Cost \\
\hline GP visits & $0.29(0.05)$ & $22.70(4.25)$ & $0.55(0.08)$ & $42.96(6.40)$ \\
\hline ER visits & $0.07(0.02)$ & $29.51(8.21)$ & $0.11(0.03)$ & $47.72(11.44)$ \\
\hline Inpatient nights & $0.04(0.03)$ & $71.40(54.93)$ & $0.27(0.10)$ & $\begin{array}{l}505.10 \\
(190.54)\end{array}$ \\
\hline Antibiotic costs \# & $7.83(1.55)$ & $14.20(2.04)$ & $11.94(1.61)$ & $29.08(3.14)$ \\
\hline $\begin{array}{l}\text { Oral corticosteroids dose } \\
\text { (mg) }\end{array}$ & $250.80(43.20)$ & $5.02(0.86)$ & $487.38(90.66)$ & $9.75(1.81)$ \\
\hline Antimicrobial resistance & & $172.82(4.62)$ & & $31.97(3.03)$ \\
\hline Combination therapy & & $16.40(5.46)$ & & $15.86(3.41)$ \\
\hline Inhaled steroids & & $18.86(5.67)$ & & $17.81(3.53)$ \\
\hline $\begin{array}{l}\text { Other prescribed } \\
\text { medicines }\end{array}$ & & $9.36(2.18)$ & & $9.08(1.91)$ \\
\hline OTC cost & & $15.06(2.92)$ & & $17.34(2.86)$ \\
\hline \multicolumn{5}{|c|}{ Overall costs } \\
\hline Intervention cost & & $413.14(9.51)$ & & 0 \\
\hline Healthcare cost & & $\begin{array}{l}584.19 \\
(60.64)\end{array}$ & & $\begin{array}{r}661.49 \\
(199.80)\end{array}$ \\
\hline Societal cost & & $\begin{array}{l}1256.47 \\
(107.25)\end{array}$ & & $\begin{array}{l}1512.69 \\
(275.04)\end{array}$ \\
\hline \multicolumn{5}{|c|}{ Exacerbations } \\
\hline Moderate exacerbations & \multicolumn{2}{|c|}{$0.39(0.05)$} & \multicolumn{2}{|c|}{$0.71(0.08)$} \\
\hline Severe exacerbations & \multicolumn{2}{|c|}{$0.48(0.06)$} & \multicolumn{2}{|c|}{$0.85(0.10)$} \\
\hline Total exacerbations & \multicolumn{2}{|c|}{$0.87(0.09)$} & \multicolumn{2}{|c|}{$1.56(0.13)$} \\
\hline
\end{tabular}


Table 2: Differences in mean costs (Placebo minus Azithromycin group)

\begin{tabular}{|c|c|c|c|c|}
\hline & \multicolumn{2}{|c|}{ Mean difference } & \multicolumn{2}{|c|}{ 95\% Confidence interval } \\
\hline & Visits/nights/units & Cost & Visits/nights/units & Cost \\
\hline GP visits & $0.26 * *$ & $20.25^{* *}$ & $0.07-0.45$ & $5.23-35.27$ \\
\hline ER visits & 0.04 & 18.21 & $-0.02-0.10$ & $-9.34-45.75$ \\
\hline Inpatient nights & $0.23^{*}$ & $433.70^{*}$ & $0.03-0.43$ & $48.59-818.81$ \\
\hline Antibiotic costs & 4.10 & $14.88^{* *}$ & $-0.29-8.50$ & $7.55-22.21$ \\
\hline $\begin{array}{l}\text { Oral corticosteroids dose } \\
\text { (mg) }\end{array}$ & $236.58^{*}$ & $4.73^{*}$ & $40.92-432.23$ & $0.82-8.64$ \\
\hline Antimicrobial resistance & & $-140.83 * *$ & & $-151.76--129.90$ \\
\hline Combination therapy & & -0.54 & & $-13.28-12.20$ \\
\hline Inhaled steroids & & -1.05 & & $-14.27-12.17$ \\
\hline $\begin{array}{l}\text { Other prescribed } \\
\text { medicines }\end{array}$ & & -0.27 & & $-5.99-5.44$ \\
\hline OTC cost & & 2.28 & & $-5.76-10.33$ \\
\hline \multicolumn{5}{|c|}{ Overall costs } \\
\hline Intervention cost & & -413.14 & & \\
\hline Healthcare cost & & 77.30 & & $-328.29-482.90$ \\
\hline Societal cost & & 256.22 & & $-318.04-830.48$ \\
\hline \multicolumn{5}{|c|}{ Exacerbations } \\
\hline Moderate exacerbations & $0.32 * *$ & & $0.13-0.52$ & \\
\hline Severe exacerbations & $0.37^{* *}$ & & $0.14-0.59$ & \\
\hline Total exacerbations & $0.69 * *$ & & $0.38-1.00$ & \\
\hline
\end{tabular}

${ }^{* *} p<0.01, * p<0.05$. All figures reported to 2 decimal places. \# other than intervention costs All monetary values quoted in AUS\$ 
Table 3: Net monetary benefit estimates for exacerbations

\begin{tabular}{|l|c|c|}
\hline NMB & Healthcare costs & Societal costs \\
\hline moderate exacerbations & $935.49(531.46-1343.16)$ & $1110.64(628.30-1584.63)$ \\
\hline severe exacerbations & $1051.77(568.63-1571.91)$ & $1206.85(538.68-1808.61)$ \\
\hline total exacerbations & $1910.70(1327.72-2525.64)$ & $2072.30(1348.55-2805.23)$ \\
\hline
\end{tabular}

Data are mean $(95 \% \mathrm{Cl})$, All figures reported to 2 decimal places

All monetary values quoted in AUS\$ 
Table 4: Sensitivity analyses showing net monetary benefit for moderate, severe and total exacerbations based on A) Winsorised costs B) AMR at twice upper bound cost per course, C). Utility decrement experienced over 8 weeks, and societal WTP per QALY of \$64,000. D) Exclusion of censored observations. Data are mean $(95 \% \mathrm{Cl})$.

\begin{tabular}{|l|c|c|c|c|}
\hline Analysis method & A & B & C & D \\
\hline Exacerbation & & & & \\
\hline Moderate & $1051.17(621.34-1509.39)$ & $724.90(251.26-1220.27)$ & $855.02(433.42-1261.45)$ & $1166.22(675.48-1663.27)$ \\
\hline Severe & $1173.83(563.49-1769.42)$ & $839.36(195.49-1451.85)$ & $923.81(392.95-1426.40)$ & $1107.01(454.97-1748.75)$ \\
\hline All & $2031.77(1353.49-2748.34)$ & $1700.68(990.78-2441.65)$ & $1523.32(941.44-2068.36)$ & $2094.77(1361.48-2852.22)$ \\
\hline
\end{tabular}

All monetary values quoted in AUS\$ 
Figure 1A

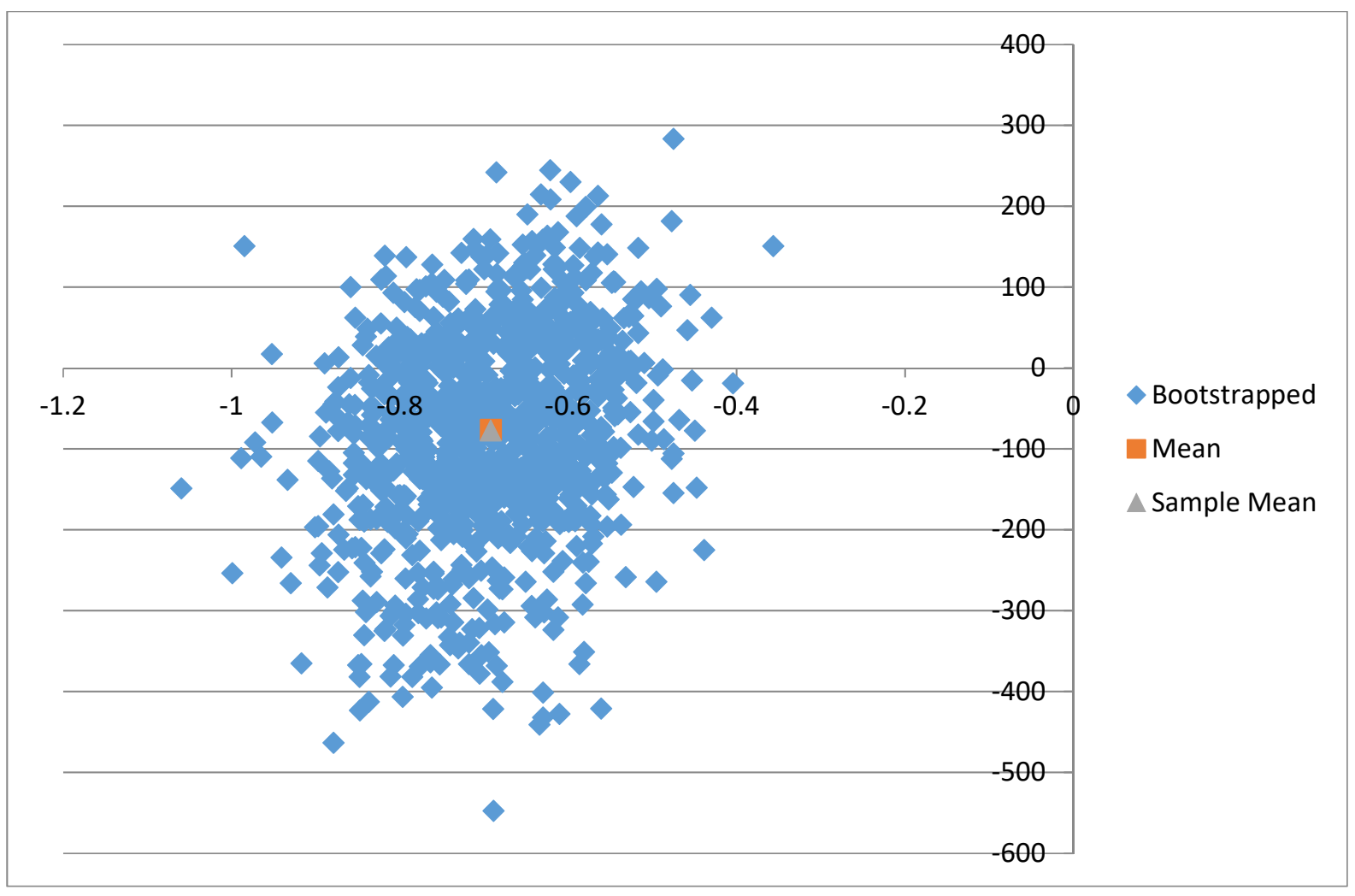

Figure 1B

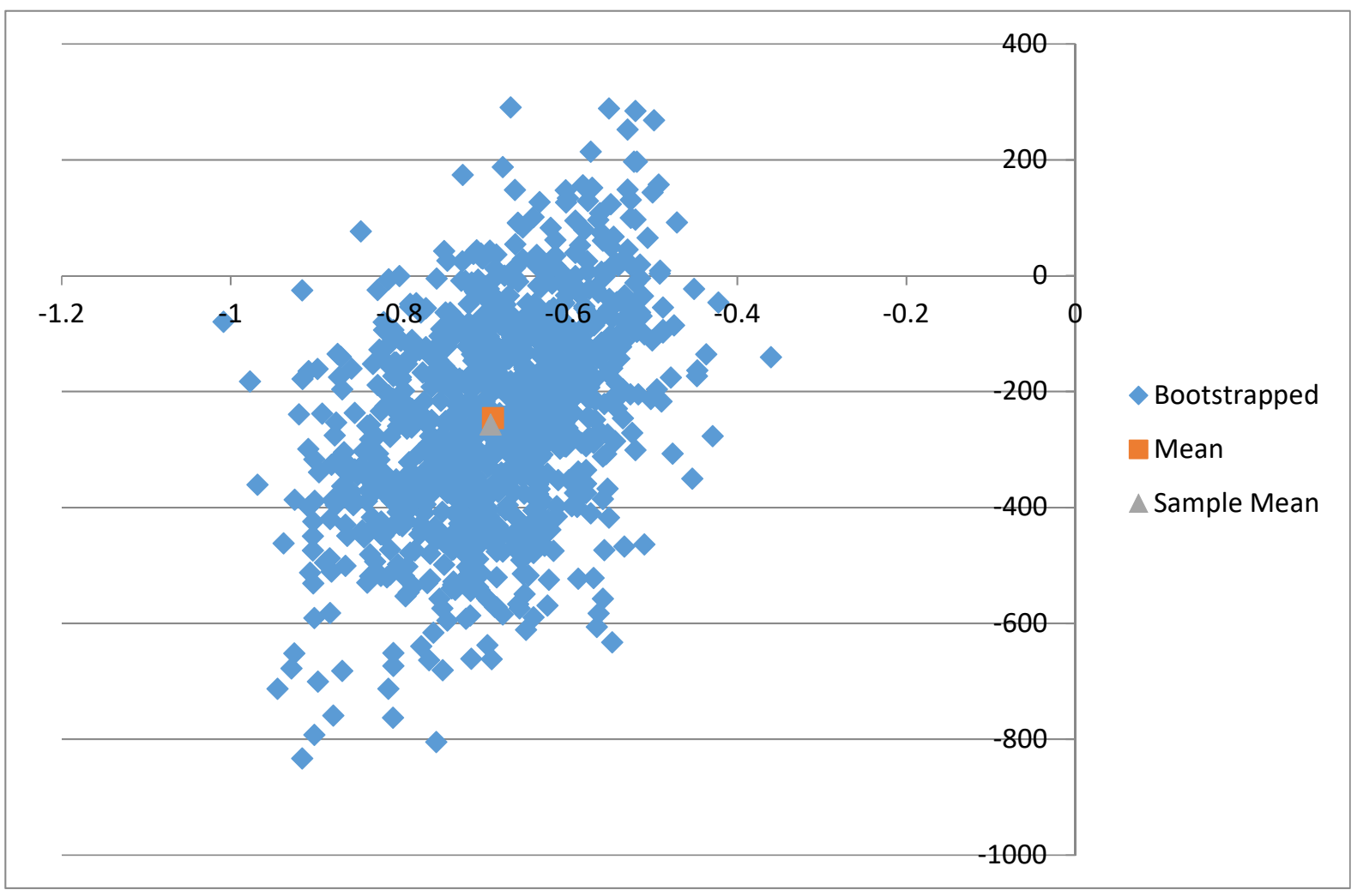


Figure 2

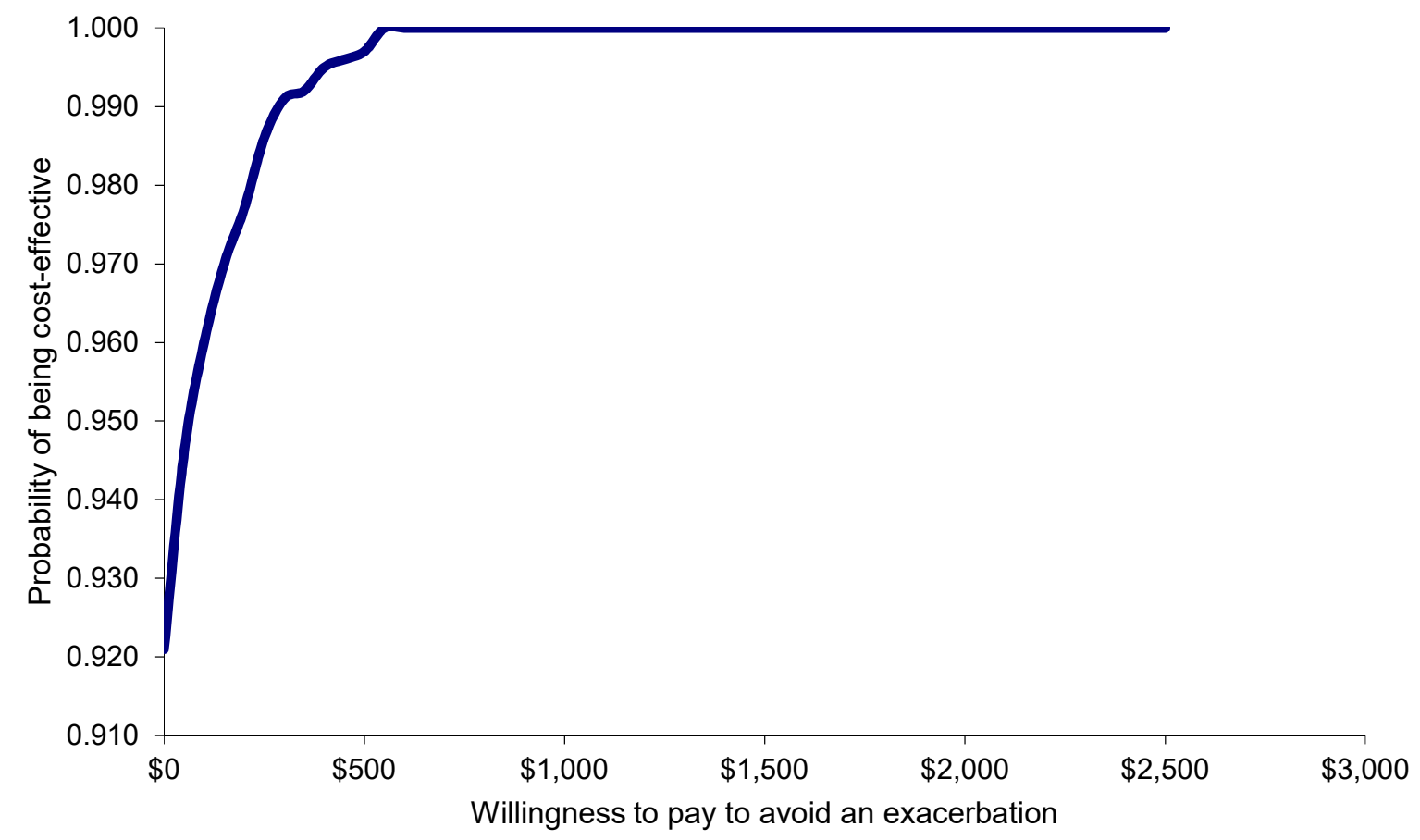




\section{Figure legend}

Figure 1: Cost-effectiveness plane:

A) incremental healthcare costs/ incremental total exacerbations

B) incremental societal costs/ incremental total exacerbations

Figure 2: Cost-effectiveness acceptability curve 